\title{
Creating a database for recording and evaluating the species of vegetation in the county of Athens, Greece
}

\author{
N. Zois ${ }^{1} \&$ A. Tsouchlaraki ${ }^{2}$ \\ ${ }^{1}$ School of Science and Technology, Open University, Greece, \\ ${ }^{2}$ Department of Environmental Engineering, \\ Technical University of Crete, Greece
}

\begin{abstract}
Urban forestry is an important part of cities and the rewards are many. The planning of urban forestry involves equally the civil works of a city as well as the water and sewage works, lines of natural gas, roads and electric power network. The creation of urban forestry normally must precede the construction of buildings.

Urban forestry includes all the outdoor-planted areas (with trees, bushes, flowers, grass). Such open areas are parks, squares, tree lanes, planted areas of homes and apartment complexes, river banks, public buildings, schools, etc. In this report the creation of a database is attempted for the recording of the types of vegetation in the county of Athens. There follows an evaluation of vegetation types based on specific criteria. Valuable conclusions are reached and specific proposals are made as far as the type of vegetation that is acceptable (based on their most valuable properties), also some new promising species of vegetation are proposed for experimentation and trial planting.

The increase of urban forestry can be made through land possessing after reimbursing private owners, improvement of existing green areas, tree lanes and finally, with planting of balconies, roof tops and open spaces. The State is called, working with the citizens, to build a better tomorrow.
\end{abstract}

Keywords: urban forestry, criteria for vegetation selection, database, environmental monitoring. 


\section{Introduction}

The basic target of this project is to consider types of biodiversity (local or otherwise) which must exist and fit in a specific area. The city of Athens was chosen as the field of investigation. The city of Athens presents one of the greatest densities of population worldwide. In order to achieve this density of population many open areas were sacrificed which could have been parks and squares. The methodology that is followed contains three steps. As a first step, we make a complete documentation (as much as possible) of the types of vegetation in the county of Athens and specifically, in parks, squares, tree lanes, around the public buildings, schools, planted private areas of homes, apartment buildings, etc. At the same time we observe on site the adaptability of every tree and bush (specifically if it develops well or if it is sickly), we take specimens (leaves, fruits), we take pictures of it, the street where the specimen is taken is recorded and its location is noted on a map of the county of Athens.

The second step is to evaluate the various vegetation types in relation to many important criteria such as: the cleaning of the air after absorption and removal of pollution by the leaves, the shading of buildings during the summer months (we have a lesser use of air conditioning) aesthetic improvement of the area, withholding of a percentage of the water by the leaves and by the soil (that results in fewer floods), also the weathering of the soil is reduced, since the roots hold the soil in place.

The final step is to propose types of vegetation for the county of Athens which respond positively to those very important criteria.

\section{Criteria of vegetation selection}

The choice criteria that play important role as far as the suitability of each type of vegetation are explained here below taking into priority the cleaning of the atmosphere from carbon dioxide and from the organic pollutants. More analytically the choice criteria of vegetation that were used in this project are:

1. Large trees are chosen with great leaf area [1]. These withhold more carbon dioxide, thus reducing the greenhouse effect. Evergreen trees are chosen so that we have $\mathrm{CO} 2$ withholding all year round (such as cypress, pines and cedars) and deciduous trees with thick leaf density (such as plane trees, maple, berry) [2].

2. We choose trees, such as pines, leylendii and cypress [3] that withhold great quantities of pollutants SO2, PM10 and PM2,5 particles and do not release organic substances (VOC-s) which are responsible for the production of harmful ozone [2]. We choose more evergreen trees so that we can have a year-round withholding of pollutants.

3. Trees that are chosen must be wind resistant. This has to do with the wood strength of each species of tree and the manner of pruning that has been done.

4. It is desired that the roots will not create problems to the subterranean networks (that usually happens from the roots of trees that develop close to 
the surface of the soil only). Watering in depth helps the movement of the roots downwards while surface watering helps the production of roots close to the surface. Roots can damage sidewalks, foundation of buildings, water networks, sewage, lighting networks, gas networks, etc. Trees correspondingly to each species must keep specific distances between each other, from buildings and from subterranean networks. For example, at a pine tree lane, the trees must keep a distance of 5,00 meters between each other while from foundations or subterranean networks, pines must keep a distance of at least 2,50 meters [4].

5. Long surviving trees are chosen (life span of 50 years or more) under the difficult conditions of the city. The great longevity of the tree depends on the adaptability which it has shown, the correct care which has taken place and its strength against disease.

6. Low maintenance trees are preferred. Those are the evergreens which do not need pruning, fertilizing, a lot of watering, etc. (such as Brachychiton, Cedrus, Ceratonia, Cypressus, Ligustrum, Citrus Aurantium and Pine).

7. Disease-free trees are chosen such as Cedrus, olive, eucalyptus, laurel and Sophora. We categorize the various species as attacked by few, medium or many diseases. The diseases are caused by viruses and bacteria. In order for the tree to succumb to the disease the following must exist:

- the environment must be polluted

- $\quad$ the tree must be damaged or wrongly pruned (very common)

- to have a lack of nourishing ingredients

- to have little or a lot of water

- the tree to be under little or a lot of sunshine

- the microclimate of the area to not favor this type of vegetation;

- Trees that use little water are proper for the dry climate of Athens (such as Acer, Albizzia Julibrissin, Casuarina, Cotinus, Pinus Nigra, Laurus Nobilis, Sophora, Tilia Tomentosa and Ulmus Campestris) [5].

8. Trees that use little water are proper for the dry climate of Athens (such as Acer, Albizzia Julibrissin, Casuarina, Cotinus, Pinus Nigra, Laurus Nobilis, Sophora, Tilia Tomentosa and Ulmus Campestris) [5].

9. The shape of the tree, its width and height so that to create a rich shade in the summer while in the winter to be deciduous allowing the sun to warm and light the area behind the tree. Such types are Morus, acer platanoides, platanus orientalis, Sophora, Acer Negundo, Tilia Tomentosa, Ulmus Campestris, and juglans regia).

10. The vegetation that is chosen must not create problems with allergies which harm someone when he comes in contact with the plant, pollen, etc. The degree of danger is marked as follows :

- negligible

- $\quad$ allergies $=$ pollen creates allergic reactions

- $\quad$ irritation $=$ some substance of the trees such as hair, oils, seeds and fumes create irritation at the neck, skin, the eyes and the nose

- $\quad$ poisonous $=$ substances which are produced by the trees can cause sickness or death 
Trees that have negligible effects are Tilia Tomentosa, Cypressus Macrocarpa, Laurus Nobilis, Sophora, Juniperus Horizontalis, Cedrus Atlantica Glauca, Ceratonia Siliqua, Cypressocyparis Leylendii, Cypressus and Sophora [1].

11. Trees are chosen that can survive in the structural soil of Athens which trees can withstand the construction of sidewalks and streets, that allow the development of roots and withhold moisture [6] such as Acer, Albizzia Julibrissin, Casuarina, Cotinus, Pinus Nigra, Laurus Nobilis, Sophora, Tilia Tomentosa and Ulmus Campestris [5].

12. Trees and bushes are chosen that are fit to the environment and to the climate of Athens, local species and species that have been tried in the past with success and belong now to the flora of the region. Such are the Cercis Siliquastrum, Morus, platanus orientalis, Olea Europaea, Brachychiton, Cedrus, Ceratonia Siliqua, Cypressus, Ligustrum, Cypressus Macrocarpa, Citrus Aurantium, Pinus halepensis, Eucalyptus, Juniperus Horizontalis, Laurus Nobilis, Cotinus and Nerium Oleander.

13. The maximum height of the tree is important when we have cables above trolley lines, etc. In that case, we must not exceed the seven meters [6].

14. Flowering time, duration, color, aroma and shape of the flowers is useful in choosing beautiful trees and shrubs.

15. Type, size, color and amount of fruits - that gives us four choices: hybrids without fruits, species with little fruit, much fruit and with fruits all year round.

16. Trash from fruits, leaves, bark and branches of trees that fall create problems in the area for the inhabitants. It is better if those trees are planted in gardens or parks where those materials do not create much of an issue and part of them becomes fertilizer (opposed to having them planted in sidewalks where cleanliness is a daily problem).

17. Some trees and bushes that have fruits, seeds, etc. attract insects, birds and small animals, thus creating a new ecosystem. At the Syngrou Park in Athens Arbutus andrachne were planted and attracted new types of birds in the area.

18. Certain trees and shrubs are more flammable. Endurance against fire is presented in trees that:

- $\quad$ have wide and large leaves

- $\quad$ present a high degree of moisture in the leaves and the remaining parts

- $\quad$ have small quantities of dead materials (branches, leaves, etc.)

19. The cost of planting includes the buying of plants, the fertilizing of the ground and the watering. Everything though is not always what it seems. For example a plant of Robinia Pseudoacacia costs 0.04 Euro while a plant of Brachychiton costs at least double the price though the first one is a very harmful tree while the second one is exceedingly useful.

The planting begins after completion of the construction of civil works such as water networks, electricity, sewage, natural gas, telephone, etc. If the duration of construction of the buildings exceeds one year then it is advisable to make the 
planting of the exterior spaces before the construction of the buildings (the planting must be protected from construction work).

Especially for tree lanes many beautiful trees can be planted sacrificing few parking positions. Those species of trees must be :

- durable in the compression of roots, little water and poor soil

- to withstand side winds and air currents that create large vehicles passing by.

- $\quad$ to absorb dust, particles PM10 and PM2,5, CO2, SO2, lead and other pollutants

- $\quad$ to not create organic pollutants damaging further the atmosphere

- $\quad$ to not create fruits, seeds, flowers that create problems (pollen, liquids, cotton such as male Populus trees

- $\quad$ to not bother cables above for example, trolleys, electric cables, etc.;

- $\quad$ to not get infected easily by viruses, insects, thus rotting slowly and suddenly collapsing and creating accidents

- $\quad$ to be evergreen and centennial so that there will be no need replacing it every 20 years or so and to be in a shape of a column or pyramidal so that there is no need for maintenance or pruning etc.

- their roots to go in depth and not to be only near the surface (which destroy the sidewalk and the subterranean networks)

- $\quad$ to be fit and tried for the local flora

- $\quad$ the safety of the vehicle movement and of the pedestrians must be taken into consideration in designing and planting of the tree lanes.

\section{Recording the vegetation}

In various walks the vegetation of Athens was investigated. Specimens of leaves, pictures of trees and many written notes were taken. This recording was done from the middle of October until the end of November 2005. The fall of 2005 was not especially rainy and that assisted in our observations. The following areas were investigated: Koukaki, Philopappou, Akropolis, Patission Avenue, Axarnon Avenue, Amerikis Square, Kato Patissia, Kipseli (Nea and Ano), Fokinos Negri, National Garden, Pedion tou Areos, Lykabettos, Exarcheia, Geoponiki School, Iera odos, Gkizi and Poligono, Syntagma Square, Plateia Americis, Botanicos.

Small differences were found as far as the species of vegetation. The proportion of vegetation per person in Athens is very small, in the order of $2 \mathrm{sq}$ meters per person. In Pedion of Areos there is a diversity of flora. Until 1935 this area used to be a military shooting ground. The National Garden includes many species of vegetation from abroad (Western Europe and Egypt). The squares of Athens for the most part includes pines, alba, palm trees while bushes preferable are Nerium Oleanders, Arbutus Adrachne, Myrtus Communis and ivies [7].

Regarding tree lanes species such as Populus, Hibiscus Syriacus, Brachychiton, Alba, Robinia Pseudoacacia, Citrus Aurantium, Cercis Siliquastrum and Platanus Orientalis were planted the last decades. 
In few gardens of the old homes of Athens, there are lemon and fig trees and more rose bushes and jasmine.

\section{Evaluation}

Investigation proves that many types of vegetation which exists in Athens especially in the local flora are absolutely proper for the area. Other species that have been imported have also become acclimatized and are useful. Some others are developing easily but also are creating many problems. Proposals are given for some species of trees that have not been planted but present certain qualities and are worthwhile to be investigated. Here below in tables 1 and 2 are presented the existing useful and harmful types of vegetation.

Table 1: $\quad$ Existing suitable species of vegetation in the county of Athens.

\begin{tabular}{|l|l|l|}
\hline \multicolumn{3}{|c|}{ EXISTING SUITABLE SPECIES OF VEGETATION } \\
\hline \multicolumn{1}{|c|}{ DECIDUOUS } & \multicolumn{1}{|c|}{ EVERGREEN } & \multicolumn{1}{c|}{ SHRUBS } \\
\hline $\begin{array}{l}\text { Albizzia } \\
\text { julibrissin }\end{array}$ & Olea europea & Jasminum polyanthum \\
\hline Casuarina & $\begin{array}{l}\text { Brachychiton } \\
\text { diversifolium }\end{array}$ & Arbutus andrachne \\
\hline $\begin{array}{l}\text { Cercis } \\
\text { siliquastrum }\end{array}$ & Cypressus Macrocarpa & $\begin{array}{l}\text { Juniperus chinensis } \\
\text { pfitzeriana }\end{array}$ \\
\hline Morus Alba & Eucalyptus globules & Juniperus horizontalis \\
\hline Morus Nigra & Cedrus atlantica & Laurus nobilis \\
\hline Acer platanoides & Cedrus Libani & Rosmarinus officinalis \\
\hline Platanus orientalis & Cedrus deodara & Euonymus japonicus \\
\hline Sophora japonica & Ceratonia ciliqua & Juniperus phoenicea \\
\hline Acer negundo & Cypressus Sempervirens & Thymus vulgaris \\
\hline Juglans regia & Ligustrum japonicum & Cotinus coggygria \\
\hline & Citrus aurantium & Lavendula officinalis \\
\hline & Pinus pinea & Picea pungens glauca \\
\hline & Pinus brutia & Nerium oleander \\
\hline & Pinus nigra & Nerium oleander \\
\hline & Pinus halepensis & Pyracantha coccinea \\
\hline & $\begin{array}{l}\text { Chamaecyparis } \\
\text { lawsoniana }\end{array}$ & Rosa species \\
\hline & Pseudotsuga menziesii & Opuntia ficus indica \\
\hline & & \\
\hline
\end{tabular}

Even though certain types of vegetation are considered unqualified still they should not be expelled from the county of Athens. They can remain adding thus to the diversity of the species of the area. At any case we are only at about $1 / 4$ and 
still remaining the $3 / 4$ of the planting for the vegetation of Athens and this future planting can be done with the proper species.

We consider the here below listed not proper for the city of Athens (Table 2).

Table 2: Existing non-suitable species of vegetation in the county of Athens.

\begin{tabular}{|c|c|c|}
\hline \multicolumn{3}{|c|}{ EXISTING NON SUITABLE SPECIES OF VEGETATION } \\
\hline DECIDUOUS & EVERGREEN & SHRUBS \\
\hline Robinia hispida & $\begin{array}{l}\text { Auraucaria excelsa } \\
\text { bidwillii }\end{array}$ & \multirow{13}{*}{$\begin{array}{l}\text { Few only are not } \\
\text { suitable, mainly } \\
\text { because they contain } \\
\text { poisonous substances, } \\
\text { especially dangerous for } \\
\text { children such as the } \\
\text { Viburnum tinus }\end{array}$} \\
\hline Robinia Pseudoacacia & Quercus ilex & \\
\hline Ailanthus altissimus & Cypressus arizonica & \\
\hline Hibiscus syriacus & Cypressocyparis leylendii & \\
\hline Salix babylonica & Magnolia grandiflora & \\
\hline $\begin{array}{l}\text { Koelreuteria } \\
\text { paniculata }\end{array}$ & Myrtus communis & \\
\hline Populus alba & Picea albertiana conica & \\
\hline Populus Nigra & Taxus baccata cono & \\
\hline $\begin{array}{l}\text { Liquidambar } \\
\text { orientalis }\end{array}$ & Thugia orientalis & \\
\hline \multirow[t]{4}{*}{ Fraxinus ornus } & Phoenix canariensis & \\
\hline & Washingtonia robusta & \\
\hline & Chamaerops excelsa & \\
\hline & Phoenix dactylifera & \\
\hline
\end{tabular}

\section{Proposed new species}

Here below are presented some species that have certain positive characteristics, so that they can be tried experimentally first in the Athenian scenery:

- Abies Nordmanniana. This tree is evergreen and has tremendous advantages. It has thick foliage, belongs to the great trees, produces negligible organic pollutants, is medium strong in the wind and the damages from the roots to the pavement are mediocre. It is suggested for city squares and parks. The maximum height of the tree reaches 22 meters. The shape is conical. It survives in moist soil and in acid or neutral ground. It prefers partially sunny locations. The fruits are pine cones. It is centennial. There are no dangers in the human health from this tree $[8,9]$.

Picea Pungens Hoopsii. It is evergreen and it has many advantages. It has thick foliage, belongs to the great trees, produces medium organic pollutants, is medium strong in the wind and the damages from the roots in the pavement are mediocre. It is suggested for city squares and parks. The 
maximum height of the tree reaches 22 meters. The shape is conical. It survives in moist soil and in acid, alkaline or neutral ground. It prefers partially sunny locations. Its seeds are pine cones. It is centennial. It creates some allergies $[8,9]$.

Cinnamonum Camphora. It is evergreen and it also has many advantages. It has thick foliage, belongs to the great trees, produces minimal organic pollutants, is strong in the wind and the damages from the roots in the pavements are high. It is suggested for city squares and parks. The maximum height of the tree above 22 meters. The shape is round, umbrella type. It survives in wet soils, in acid, alkaline or neutral ground. It prefers partially sunny locations. Its fruits are small and black like olives. The leaves are shiny light green. It is centennial. It creates some allergies [9].

Sequidendron Giganteum. It is evergreen and it has a tall beautiful sight and many advantages. It has thick foliage, it belongs to the greatest trees in the world, produces medium organic pollutants, it is strong in the wind and the damage from the roots in the pavement is mediocre. It is suggested for city squares and parks as a Christmas tree. It reaches a greatest height of 85 meters (in California, U.S.A). The shape is conical. It survives in moist and dry soil, in acid, alkaline or neutral ground. It prefers sunny locations. Its fruits are cones. It is super centennial. There are no dangers to human health from this tree [8-10].

Juniperus Oxycedrus Macrocarpa. It is an evergreen tree, up to 10 meters in height with an almost straight upward trunk. It has thick foliage with needles, hard and sharp. The fruit is spherical, dark brown - black color. It is strong to the wind. It lives over 100 years. It survives in sandy and stony locations [11].

Tilia Tomentosa. It comes from Southeast Europe. The height of this tree is 27 meters while the width can reach 12 meters. It survives up to 150 years. It is egg shaped, symmetrical. The leaves are green on top while underneath they are white. It is deciduous. The flowers are small yellow and white, with bouquet very aromatic in June and July and they cause the bees to behave dizzily. It develops in deep watery soils but it can also survive in the drought and the heat. It survives extremely cold weather. It develops to a height to 9 meters in the first 20 years. It creates a thick shade. It produces no organic pollutants. Due to the fuzzy leaves, it collects dusts and suspended particles, thus cleaning the atmosphere of the city. There are no dangers to human health from this tree [2].

Ulmus Campestris. It comes from Europe, West Asia and North Africa. It has a shape of a pyramid. It lives up to 150 years. It reaches a height of 20 meters. The leaves have an egg shape with a rough surface, dark green color and are deciduous. The flowers are small in groups red in the beginning and green later in the spring. It develops in deep rich soils, lightly alkaline. It is strong in the frost but not in the wind. It develops 10 meters high in the first 20 years. It is a perfect tree for cities with extremely destroyed and polluted environments. It presents no organic pollutants. It is proposed for parks and tree lanes [12]. 
All the above trees create negligible organic pollutants; they absorb great quantities of $\mathrm{CO} 2$ and generally have characteristics that are acceptable for the conditions of big cities. Greater investigation is needed for these species.

The Abies and Sequoias species are also highly desirable for the Christmas season.

\section{Conclusions - proposals}

From this investigation it is seen that the most qualified trees for the climate of Athens are the local species for example, Alba, Platanus Orientalis, Cypressus, Citrus Aurantium, Pine and Eucalyptus. Also greatly incorporated are the following species, Acer platanoides, Brachychiton, Cedrus, Cypressus Macrocarpa, Ceratonia Siliqua and Ligustrum. As unacceptable since they create many organic pollutants, live short time, do not offer enough shade, etc. are trees that are use widely such as Robinia Pseudoacacia, Hibiscus Syriacus, Salix, Koelreuteria Paniculata, Populus, Liquidambar orientalis, Myrtus Communis and Palm trees. As someone may very well say there are no free areas in Athens for planting of vegetation. When there is a will though there is a way. Plantings can take place in the following areas:

- $\quad$ land possessed areas. Those are abandoned lots with semi destroyed homes wherever they exist. There can be playgrounds in combination with planting of the areas.

Tree lanes. In every street of the city can be created tree lanes taking some space either from the sidewalks or from parking.

Trees can be planted at distances 1,50 meters from subterranean networks and 10-15 meters from the street intersections. We chose species whose roots grow in great depth, not creating problems in subterranean networks and in the pavement. The trees are protected by a concrete boundary of a diameter about 1 meter and in height 0,50 meters.

The existing city squares and parks can be cleaned of the dead trees and can be planted with new species wherever there is space. There can be a reevaluation of the green areas and wherever for example we have lawns there can also be planted trees since those areas are watered excessively.

In roof tops. Roof gardens and free spaces of the lots can have tax breaks to increase planting. In cooperation with the city agriculturist we can plant all possible areas in every lot that is built such as roof tops, balconies, open areas and in the ground floor.

In any case trees are chosen based on the specifications that were already explained above. Also and lastly there must be care in choosing the shape and the height of the trees whenever we have narrow streets and cables above.

\section{References}

[1] Urban Forest Ecosystems Institute, A tree selection guide, Tree List, http://selectree.calpoly.edu/Information.html 
[2] Nowak, D., Crane, D., Stevens, J., Ibarra, M., Brooklyn's Urban Forest, Forest Service, U.S.D.A.

[3] Powe, N., \& Willis, K., Mortality and Morbidity Benefits of Air Pollution, Absorption by Woodland, University of New Castle, http://www.newcastle.ac.uk/cream/

[4] Center of Environmental Education, Planting Instructions http://kpeakrat.ach.sch.gr/ideas_2.html

[5] All about Trees, Ortho Books, Chevron Chemical Company, 1982.

[6] Urban Tree Species Guide, SC Forestry Commission http://www.state.sc.us/forest/urbsg4.htm

[7] City of Athens, Portal, 11000 trees planted in Athens, 25.10.2004

[8] Garden Center Siniolakis, Afidnes, Attica, http://www.siniolakis.gr

[9] Urban Forest Ecosystems Institute, A tree selection guide, Tree List, http://selectree.calpoly.edu/Information.html

[10] Vasilakos Nurseries, http://www.vasilakos.gr/

[11] Sfikas, G., Trees and Shrubs of Greece, Eustadiadis group A.E. Athens

[12] Tsalakidis, J., Decorative Plants for Greek Gardens, Paratiritis, Thessaloniki, Greece, 1994. 